\title{
Research on Financial Early Warning of Real Estate Listed Companies
}

\author{
Jinyue Liu ${ }^{\mathrm{a}}$ Hongmei Zhang ${ }^{\mathrm{b}}$ \\ School of Big Data Application and Economics, Guizhou University of Finance and Economics \\ Guiyang 550025, China
}

a.2431269208@qq.com,b.zhm1035@qq.com

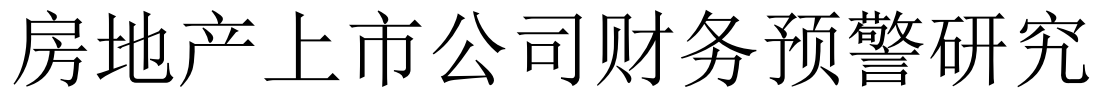

刘金月 ${ }^{\mathrm{a}}$ 张红梅 $^{\mathrm{b}}$

贵州财经大学大数据应用与经济学院

贵阳 550025，中国

a.2431269208@qq.com, b.zhm1035@qq.com

\begin{abstract}
Since the beginning of the 21 st century, the real estate industry has become an important engine to promote economic development. Moreover, it has entered a critical period of history. At the same time, the real estate industry has become a distribution center of capital and risk in the national economy because of its high correlation with financial support. Based on principal component analysis and logistic regression model analysis, this paper chooses evaluation indexes from six aspects: profitability and growth ability, profitability, solvency, operation ability, development ability, investor benefit guarantee index and cash flow index, and establishes financial early warning model of real estate listed companies. The empirical results show that the accuracy of early warning is 83.3\%.
\end{abstract}

Keywords-Financial Risk, Real Estate Listed Companies, Financial Risk Early Warning

摘要一从 21 世纪初开始, 房地产行业已成为推动经济发 展的重要引擎。目前我国已走进历史关键时期。同时由于房 地产行业因为与金融支持高度相关的特点，成为国民经济中 资本与风险的集散地。本文基于主成分分析法和 logistic 回 归模型分析, 从盈利能力和成长能力盈利能力、偿债能力、 营运能力、发展能力、投资者利益保障指标、现金流量指标 等 6 个方面选取评价指标, 建立了房地产上市公司财务预警 模型。实证表明其预警准确率为 $83.3 \%$ 。

关键词一财务风险，房地产上市公司，财务风险预警

\section{I. 引言}

没有危机意识的民族，必然是不幸的民族，必然是 没有创新能力的民族。强有力的风险管理，是民族危机 意识的必然产物 ${ }^{[1]}$ 。近些年来，随着改革开放至今 30 年, 我国经济水平提升,城市化进程大大加快，而房地产行业 在短短 10 多年时间里, 从 21 世纪初开始已成为推动经 济发展的重要引擎, 成为国民经济的重要支柱。房地产
的发展不仅直接影响前向和后向相关产业的发展, 还因 为与金融支持高度相关的特点, 成为国民经济中资本与 风险的集散地，泡沫经济往往是金融和经济危机的前奏。 我国加入 WTO 后, 房地产企业不仅要面对与本国同行业 企业的竞争,同时还面 临着与国外房地产企业的竞争. 因 而对我国房地产 行业竞争进行研究也势在必行 ${ }^{[2]}$ 。

房地产业是进行房地产投资、开发、经营、管理 和服务的行业, 具有基础性、先导性、带动性的行业 特征; 产业链长、投资量大、投资周期长、投资风险 大, 是一个典型 的周 期性波动的行业 ${ }^{[3]}$ 。在危机之前房 地产是涨的最快的资产, 在香港、澳门、马来西亚皆是 如此。而危机以后, 房地产也是跌的最多的资产。国际 上, 很多国家过去十几年都不同程度上经历过房地产。 我国房地产业以上世纪 80 年代为开端,经历了一系列变 革和进化, 并最终在本世纪的第一个十年走向高潮。作 为拉动中国经济的有力引擎，房地产业目前已走进历史 关键时期。由于融资形式单一带来的筹资风险、由于经 济转轨时期的中国房地产带来的投资风险、由于缺少整 体规划没有考虑到整体行情以及政府的政策变动的经营 风险、由投资者带来的收益分配风险等都是我国现有存 在的风险。我国的房地产企业, 特别是大型房地产企业 大都由国有资本控制或者本身就是国有企业转化而 来, 国有企业所具有的诸如效率较低、管理水平欠缺、内部 激 励与约束机制不健全等缺陷时有体现 ${ }^{[4]}$ 。

因此, 为了减少此类现象的发生, 现代企业必须充 分了解财务风险的成因，建立完善风险控制机制，防范 和化解企业发展中的各种财务风险, 确保企业向着合理、 科学、健康的方向发展。财务预警可以实时监控企业在 生产经营过程中的财务风险问题，可以令企业管理层更 加容易探求到企业潜在风险的缘由, 及时规避风险, 防 止企业陷入危机。 


\section{II. 文献回顾}

单变量模型（Univariate model）是由美国教授 Beaver 于 1966 年提出，他选取美国 1954-1964 年间资产 规模相同的 79 家经营失败企业和 79 家正常经营的企业 进行对比研究。使用了 30 个财务比率作为变量, 对这些 公司进行了一元变量的判定预测，发现现金流量与总资 产的比率最能有效地判定公司所面临的财务困境, 其次 是资产负债率。并且这些指标的实效性越强, 预见性也 就越强, 即误判率越低。多变量模型（Multivariate model）是是美国教授 Altman 于 1968 年提出的 Z 计分模 型。Altman 选取美国 1946-1965 年间提出破产申请的 33 家公司和同样数量的非破产公司进行对比研究。Altman 采用 Fisher 距离进行线性分析, 从 20 多个财务指标中综 合出 4-5 个模型变量, 即营运资本/总资产、留存收益/总 资产、息税前收益/总资产、股东权益/总负债、销售收 入/总资产，在分析这些变量相关性的基础上，建立了多 元线性的 $Z$ 分数预测模型。并计算 $Z$ 值得出: $Z>2.675$, 表明该企业财务状况良好， $Z<1.81$, 表明该企业具有较 大的破产风险。该方法可以通过严格的数理推算和统计 检验进行客观的评价, 应用广泛, 预测效果较好。多元 逻辑回归模型是由美国教授 Martin 于 1977 年用来预测 公司的破产和违约概率。Martin 从 1970-1977 年间大约 5700 家美联储成员银行中界定出 58 家困境银行，并从 25 个财务指标中选取总资产净利润率等 8 个财务比率, 建立了 Logistic 模型, 用来预测公司的破产和违约概率。

\section{III. 房地产上市公司财务风险评估}

风险，就是生产目的与劳动成果之间的不确定性， 财务风险是包含有企业可能丧失偿债能力的风险和股东 收益的可变性。风险的本质是由风险的特性决定 ${ }^{[5]}$ 。风 险是客观性存在的、不确定的、收益与损失共存性、全 面性的。风险处处存在, 时时存在。也就是说, 财务风 险不以人的意志为转移, 人们无法回避它, 也无法消除 它，只能通过各种技术手段来应对风险，进而避免风险。

“预警” 的重要功能就是 “预报险情”，即要求预 警体系能在资金的运营出现问题或者财务状况出现恶化 之前, 及时地发出警报, 并使决策层或管理者一看就知 道、一分析就明了 ${ }^{[6]}$ 。所谓财务预警机制, 就是利用数据 化管理方式, 对单位日常财务运行情况进行连续有效的 监测, 将潜在风险预先告知管理者的一套工具 ${ }^{[7]}$ 。对财务 风险预警分析来源于对财务报表的分析。以企业的对财 务报表为依据, 利用各种财务比率或数学根型, 对企业 的财务状况进行检验, 预测企业对财务失败的可能性。 财务指标的选取需要满足高敏感性、先兆性、全面性等 特点。

样本选取及初始财务指标选取。在经济生活中许多 现象都是以分类变量, 而不是连续变量来表示的, 研究 变量的取值只有两类情况, 即 “是”与 “否”。对于分 类变量的分析, Logistic 回归模型仍然具有不可替代的 作用。Logistic 回归模型是指因变量为二级计分或二类 评定的回归分析，一般形式如下:

$$
L_{n}=\left(\frac{p_{i}}{1-p_{i}}\right)=\alpha+\sum_{k=1}^{k} \beta_{k} x_{k i}
$$

风险, 就是生产目的与劳动成果之间的不确定性, 财务风险是包含有企业可能丧失偿债能力的风险和股东 收益的可变性。风险是客观性存在的、不确定的、收益 与损失共存性、全面性的。风险处处存在, 时时存在。 也就是说, 财务风险不以人的意志为转移, 人们无法回 避它, 也无法消除它, 只能通过各种技术手段来应对风 险, 进而避免风险。

对财务风险预警分析来源于对财务报表的分析。以 企业的对财务报表为依据, 利用各种财务比率或数学根 型, 对企业的财务状况进行检验, 预测企业对财务失败 的可能性。财务指标的选取需要满足高敏感性、先兆性、 全面性等特点。

其中,$Z=\beta_{0}+\beta_{1} X_{1}+\ldots+\beta_{n} X_{n}$ 表示常量, $\beta_{n}$ 表示对应的回归系数。 $X_{n}$ 代表各指标变量。因变 量 $P$ 表示企业出现 $\mathrm{p}$ 的概率， $P$ 越接近 0 表示企业违 约风险越低, $P$ 越接近于 1 表示企业违约风险越高。

在已知 $\alpha$ 和 $\beta_{k}$ 的情况下, 某一特定情况（以 1 表 示）发生的概率通过以下等式得到:：

$$
p=\frac{\exp \left(\alpha+\sum_{k=1}^{k} \beta_{k} x_{k i}\right)}{1+\exp \left(\alpha+\sum_{k=1}^{k} \beta_{k} x_{k i}\right)}
$$

财务危机概念的界定。根据证监会规定, 当一个公 司连续两年亏损或者净资产低于股票面值的时候, 在股 票名称前就会加上 “ST”，意为 “特殊处理”，每天的 涨跌都不得超过 $5 \%$ ，警示投资者注意投资风险。当第 三年, 公司的经营未有改善, 依旧处于亏损状态, 股票 名称前除 “ST” 外还会加上 “*”，意为退市风险。本 文是以受到特别处理 ST 和*ST 的上市公司作为有财务 危机的上市公司。

考虑到目前的实际状况和财务预警的可行性,遵循前 面所述的指标选取原则, 按照《企业效绩评价操作细则 (修订)》和证监会对上市公司信息披露要求,财务预警指 标体系应包括偿债能力、现金流动能力、发展能力、营 运能力、盈利能力等 ${ }^{[8]}$ 。最终选取了净资产收益率、营 业利润率、成本费用利润率、营业利润/营业总收入、净 利润增长率、总资产增长率、每股净资产、每股收益、 总资产现金回收率、经营净现金流量/带息债务、固定资 产周转率等 18 个指标作为因子来研究破产风险。本文的 指标数据主要来源于 RESSET 金融研究数据库。

\section{LOGISTIC 模型建立}

因财务状况而特别处理的 $\mathrm{A}$ 股上市公司作为篮选条 件, 选取 2008 年到 2018 年因财务异常而被证监会实施 $\mathrm{A}$ 股上市公司为研究对象, 并且按照 1: 1 的比例选取同 年度 21 家非 ST 公司作为配对样本, 将上市公司被 ST 的前一年的 42 家财务数据作为研究样本。从中挑选 34 家数据为训练样本 (17 家 ST 和 17 家非 ST) , 8 家数据 为预测样本 (4 家 ST 和 4 家非 ST)。对于满足正态性 检验的指标进行独立样本 $\mathrm{T}$ 检验, 对于不满足正态性检 验的财务指标进行非参数检验。最终选取有有显著性差 异的变量。如表 1 所示, X1、X2、X3、X8、X9、X10、 $X 11 、 X 12 、 X 16 、 X 17 、 X 18$, 具有显著性差异的变量。 
表 1 .指标选择表

\begin{tabular}{|c|c|c|}
\hline 变量 & 指标 & $\begin{array}{c}\text { 是否有显 } \\
\text { 著差异 }\end{array}$ \\
\hline $\mathrm{X} 1$ & 净资产收益率 (TTM) & 有 \\
\hline $\mathrm{X} 2$ & 营业利润率 & 有 \\
\hline X3 & 成本费用利润率 & 有 \\
\hline $\mathrm{X} 4$ & 流动比率 & 无 \\
\hline X5 & 速动比率 & 无 \\
\hline X6 & 资产负债率 & 无 \\
\hline$X 7$ & 应收账款周转率 (次) & 无 \\
\hline X8 & 营业利润/营业总收入 (TTM) & 有 \\
\hline X9 & 净利润增长率 & 有 \\
\hline $\mathrm{X} 10$ & 总资产增长率 & 有 \\
\hline $\mathrm{X} 11$ & 每股净资产 (元/股) & 有 \\
\hline $\mathrm{X} 12$ & 每股收益 (元/股) & 有 \\
\hline $\mathrm{X} 13$ & 每股公积金 (元/股) & 无 \\
\hline X14 & $\begin{array}{c}\text { 每股经营活动现金流量 } \\
\text { (TTM) (元/股) }\end{array}$ & 无 \\
\hline X15 & 经营现金净流量/经营净收益 & 无 \\
\hline $\mathrm{X} 16$ & 总资产现金回收率 & 有 \\
\hline $\mathrm{X} 17$ & 经营净现金流量/带息债务 & 有 \\
\hline X18 & 固定资产周转率 (次) & 有 \\
\hline
\end{tabular}

运用 spss17 软件对 34 家企业数据进行主成分分析, 提取主成份因子。样本数据处理与检验。

有效样本数量为 34 个。用 $\mathrm{KMO}$ 和 Bartlett 法对指 标体系进行检验, 一般来说, $\mathrm{KMO}$ 值大于 0.5 时, 数据 是比较适合做主成分分析的, 当 $\mathrm{KMO}$ 值小于 0.5 , 数据 就不适合做主成分分析。表 2 中显示的 KMO 值为 0.534 , 大于 0.5 , 显着性水平小于 0.5 , 表明该数据适合做主成 分分析 ${ }^{[9]}$ 。

表 2. KMO 和 Bartlett 检验

\begin{tabular}{cccc}
\hline KM0 取样 & \multicolumn{3}{c}{ 巴特利特球形度检验 } \\
$\begin{array}{c}\text { 适切性量 } \\
\text { 数 }\end{array}$ & 近似卡方 & 自由度 & 显著性 \\
0.534 & 520.456 & 55 & 0 \\
\hline
\end{tabular}

为了降低所选 11 个评价指标的多重相关性, 本文采 用主成分分析法。碎石图是反映各个因子的重要程度,
因子越重要, 特征值越大, 直线越陡峭。所得碎石图如 图 1 所示。由图 1 可知, 前 4 个指标的特征值均大于 1 , 依据总方差及旋转后的成份矩阵综合计算分析, 选取前 4 个主成分因子分别定义为 F1,F2,F3,F4 且由这 5 个主成 分因子解释了总方差的 $76.421 \%$, 解释程度较高, 这四 个主成分因子基本包含了所有指标信息。

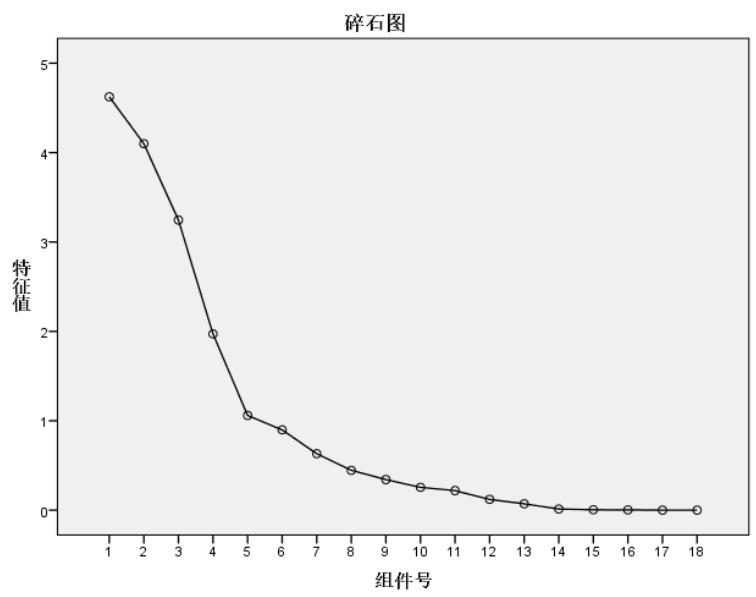

图1 碎石图

这 5 个因子分别定义为: F1 主要表示了净资产收益 率、成本费用利润率、每股净资产和每股收益等指标, 主要代表企业的盈利能力。F2 主要表示经营净现金流 量/带息债务、固定资产周转率, 反映了企业的资金周转 率。F3 主要表达了成本费用利润率, 主要代表了企业的 偿债能力。

表3. 旋转后的成分矩阵

\begin{tabular}{ccccc}
\hline & \multicolumn{4}{c}{ 成分 } \\
指标 & $\mathbf{1}$ & $\mathbf{2}$ & $\mathbf{3}$ & $\mathbf{4}$ \\
净资产收益率(TTM) & .710 & -.085 & -.072 & -.065 \\
营业利润率 & .333 & .883 & -.042 & -.247 \\
成本费用利润率 & .701 & .144 & -.555 & .310 \\
营业利润/营业总收 & & & & \\
入(TTM) & .333 & .883 & -.042 & -.247 \\
净利润增长率 & .666 & -.110 & -.565 & .356 \\
总资产增长率 & .557 & -.632 & .148 & -.091 \\
每股净资产 (元/股) & .753 & -.233 & .377 & -.281 \\
每股收益(元/股) & .861 & -.140 & .161 & -.237 \\
总资产现金回收率 & .060 & .543 & .402 & .390 \\
经营净现金流量/带 & & & & \\
息债务 & .204 & .072 & .455 & .624 \\
固定资产周转率(次) & .501 & & & \\
\hline 按照表 3 成分得分系数矩阵, 通过公式 $\mathrm{FACi}=\sum C_{i j}$ \\
得出备因子表达式为:
\end{tabular}
得出各因子表达式为:

将表中的数据带入表达式中: 
V. 结论与讨论

$F i=b i l \mathrm{x}_{1}+b i 2 \mathrm{x}_{2}+\ldots+b i m \mathrm{x}_{\mathrm{m}}(i=1,2, \cdots, m)$

$\mathrm{F} 1=0.71 \mathrm{X} 1 \mathrm{x}_{1}+0.333 \mathrm{x}_{2}+0.701 \mathrm{x}_{3}+0.333 \mathrm{x}_{8}+0.666 \mathrm{x}_{9}+0.5$ $57 \mathrm{x}_{10}+0.753 \mathrm{x}_{11}+0.861 \mathrm{x}_{12}+0.06 \mathrm{x}_{16}+0.204 \mathrm{x}_{17}+0.501 \mathrm{x}_{18}$

$\mathrm{F} 2=.085 \mathrm{X} 1 \mathrm{x}_{1}+0.883 \mathrm{x}_{2}+0.144 \mathrm{x}_{3}+0.333 \mathrm{x}_{8}+0.666 \mathrm{x}_{9}+0.6$ $32 \mathrm{x}_{10}+0.233 \mathrm{x}_{11}+0.161 \mathrm{x}_{12}+0.543 \mathrm{x}_{16}+0.072 \mathrm{x}_{17}+0.089 \mathrm{x}_{18}$

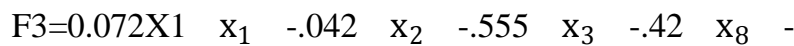
$.565 \mathrm{x}_{9}+0.148 \mathrm{x}_{10}+0.377 \mathrm{x}_{11}+0.161 \mathrm{x}_{12}+0.402 \mathrm{x}_{16}+0.455 \mathrm{x}_{17}+$ $0.446 \mathrm{x}_{18}$

$\mathrm{F} 4=0.065 \mathrm{x}_{1}-.247 \mathrm{x}_{2}+0.31 \mathrm{x}_{3}-.247 \mathrm{x}_{8}+0.356 \mathrm{x}_{9}-$ $.091 \mathrm{x}_{10}+0.281 \mathrm{x}_{11}+0.237 \mathrm{x}_{12}+0.39 \mathrm{x}_{16}+0.624 \mathrm{x}_{17}+0.145 \mathrm{x}_{18}$

将上述提取的 4 个主成分因子作为协变量, 企业破 产概率为因变量, 由于企业只会出现违约和不违约两种 情况。 logistic 模型的基本原理是把因变量分为对立的两 个结果。故本文采二分类的 logistic 回归模型进行实证分 析，并将被 ST 的企业定义为 “ 1 ”，非 ST 企业定义为 “0”。Logistic 模型都会犯两类错误, 即 I 类错误（误 拒错误, 将财务危机公司误判为非财务危机公司 ) 和 II 类错误 (误受错误, 将非财务危机公司误判为财务危机 公司）。在财务危机预警的相关研究文献中, 研究者通 常将临界阈值设定为 0.5 。根据建立的 logistic 回归模型, 其中 表示企业违约概率:

$$
P=\frac{\exp \left(3.454 \mathrm{~F}_{1}+1.347 \mathrm{~F}_{3}\right)}{1+\exp \left(3.454 \mathrm{~F}_{1}+1.347 \mathrm{~F}_{3}\right)}
$$

表4 方程中的变量

\begin{tabular}{ccccc}
\hline & $\mathbf{B}$ & $\begin{array}{c}\text { 标准误 } \\
\text { 差 }\end{array}$ & 瓦尔德 & 显著性 \\
FAC1_1 & -2.088 & 0.866 & 5.818 & 0.016 \\
常量 & -0.292 & 0.482 & 0.366 & 0.545 \\
FAC1_1 & -3.454 & 1.551 & 4.956 & 0.026 \\
FAC3_1 & 1.347 & 0.902 & 2.233 & 0.135 \\
常量 & -0.179 & 0.58 & 0.096 & 0.757 \\
\hline
\end{tabular}

模型预测正确率将预测集样本数据代入预测模型中 进行模型效果检验, 得到的检验结果如表5所示。判定 结果显示, 21 家ST 公司有 6家错判, 准确率为66\%, 21 家 ST 公司有 2 家错判, 准确率为 $98 \%$, 总体判定准确率 达到 $83.3 \%$ 。

\begin{tabular}{ccc}
\multicolumn{3}{c}{ 表5. 预测表 } \\
\hline 1 & 0 & 综合预测 \\
$66 \%$ & $98 \%$ & $83.30 \%$ \\
\hline
\end{tabular}

从以上分析中可以看出, 大体来说logistic模型在评 价房地产企业破产风险准确度较高, 具有一定的操作性 和可行性。
本文以沪深两市 $\mathrm{A}$ 股上市公司的 42 家房地产企业为 样本进行实证研究, 通过企业的从盈利能力和成长能力 盈利能力、偿债能力、营运能力、发展能力、投资者利 益保障指标、现金流量指标等 6 个方面选取 18 个评价指 标，通过主成分分析得到了四个主成分因子，并基于 logistic 模型构建房地产上市公司，实证结论如下：

1.非财务危机公司与财务危机公司在指标净资 产收益率、净资产收益率、营业利润率、营业利润/ 营业总收入、净利润增长率、总资产增长率、每股 净资产、每股收益、总资产现金回收率、经营净现 金流量/带息债务、固定资产周转率上有显著差别。 因此，本文构建的房地产上市公司财务危机预警指 标体系具有可预测性。

2. 实证过程中将 18 个指标进行整合得到 4 个 主成分因子, 从而得到企业的违约概率公式:

$$
P=\frac{\exp \left(3.454 \mathrm{~F}_{1}+1.347 \mathrm{~F}_{3}\right)}{1+\exp \left(3.454 \mathrm{~F}_{1}+1.347 \mathrm{~F}_{3}\right)}
$$

3. 该模型总体预测准确度较高, 达到了 $83.3 \%$, 这为房地产公司财务风险评价提供了较好的参考模 型. 为了遏制我国房地产行业破产风险的出现, 从全 文模型分析, 可以从如下方面入手：（1）大力提 高房地产企业自身盈利能力和现金流量。只要企业 有足够的利润和现金流量, 企业出现破产的可能性 就会大大降低。（2）协调好各个指标的关系, 做 到企业的偿债能力、盈利能力、企业自身成长能力 协调发展。可以进一步将本文研究结果应用到企业 的实践当中，对房地产企业的财务状况做出准确预 测, 以规范财务治理, 优化企业投融资结构、经营 策略及人才培养方案等, 形成企业健康发展的长效 机制。房地产不仅具有一般商品的特性, 而且还具 有社会公共产品的特性, 其社会功能是不可被替代 的。为了体现房地产的社会属性, 政府应该 从税收 设置上凸显房地产的社会共性 ${ }^{[10]}$ 。对规范上市公司 财务治理等具有现实意义。

\section{致谢}

本研究得到国家自然科学基金地区项目《贷款风险补 偿资金对科技型中小企业信贷配给的影响机理研究》 （71263011）、《基于文本信息的科技型中小企业信用风 险识别机理研究》(71861003) 的大力资助。

\section{参考文献}

[1] 黄崇福, “综合风险管理的梯形架构,” Journal of Risk Analysis and Crisis Response, vol. 14, issue 6, pp.2-10, 2005.

[2]吴朝阳, “我国房地产行业竞争初探,” Journal of Shanghai Jiaotong University, vol. 29, issue 6, pp. 58-60, 2011.

[3] 袁玲, “房地产行业薪酬设计研究,” journal of Hunan business college, vol. 12, issue 3, pp. 37-38, 2005.

[4] 盛光明, 周会, “房地产企业财务风险研究,” Journal of beijing institute of technology(social sciences edition), vol. 7, issue 4, pp. 47-50, 2005.

[5] 黄崇福, “自然灾害风险分析的基本原理,” Journal of Risk analysis and Crisis Response, vol. 8, issue 2, pp.2-10, 1999. 
[6] 张舒华, “基于 DEA 模型的高校财务预警指标体系研究, ” Journal of Changzhou Institute of Technology, vol. 24, issue 5, pp. 67-72, 2011.

[7]印巧云，“高校财务预警体系初探，” Journal of Nantong vocational college, vol. 22, issue 1, pp. 41-43, 2008.

[8] 李志强, “财务预警指标拓展研究探析, ” Journal of Henan university(Social Science), vol. 49, issue 3, pp. 34-38, 2009.
[9] 何晓群, 多元统计分析. 北京: 中国人民大学出版社, 2015 年, pp. 101-105.

[10] 王升, “房地产定价与公司财务风险度量研究,” Journal of South hina agricultural university (socal science edition), vol. 7, issue 3, pp. 50-56, 2008. 